\title{
APUNTES PARA UN ESTUDIO SOBRE LA LEGALIDAD ORGANIZACION JURIDICA Y SOCIEDAD EN CHILE HASTA LA GUERRA DEL PACIFICO
}

Miguel de Althaus

El Dr. Althaus estudia la configuración del Estado y la sociedad chilenas en la época de la Guerra del Pacífico en base a la siguiente hipótesis: "En Chile existia un abismo social y sobre ese abis mo se erguía un Estado moderno para la época y modernizante... El abismo social en Chile era de distintas caracteristicas al abismo social peruano y va a ser factor influyente en el desencadenamiento de la guerra, y el Estado modernizante chileno aparentemente se parecía a algunos Estados moder nizantes europeos, pero en la realidad se diferenció de éstos en que autolimitó su modernización, sobre todo después de la guerra, o quizás su modernización estaba en parte limitada por la situación de Chile frente a paises capitalistas avanzados".

El trabajo realiza este estudio a partir del método histórico-jurídico, combinado con la aproximación sociológica. Hace un perfil del sistema político chileno de la época, de los rasgos más saltantes de su Estado y de la sociedad que lo conforma, para concluir en una apreciación sobre la importancia $y$ los limites que tal situación tuvo en las contingencias de la Guerra del Pacifico.

Ocurre que frecuentemente solemos preguntarnos si el Perú y Bolivia pudieron haber ganado la guerra que Chile les declaró en 1879 .

¿Si hubiesen llegado los blindados que el Perú trató de adquirir durante la contienda? ¿Si los hubiera mandado construir antes que la guerra empezara, proyecto que realmente existió y que de llevarse a cabo quizás hubiese evitado la contienda? ¿Si Bolivia hubiese tenido una marina para defender su litoral? ¿Si el Perú no hubiese tenido una obvia inferioridad de armamentos frente a Chile? 
Los estudios sobre la sociedad y el Estado en el Perú de 1879 pueden resumirse en la siguiente expresión de Jorge Basadre sobre cuya vigencia actual debemos reflexionar:

"El Perú iba a ser el pais atacado e invadido en la guerra y. por consiguiente, el que más severamente debía enfrentar su prueba. Para no poder resistir las tensiones a ella inherentes tenia dos fallas esenciales que, si continúan existiendo, pueden llevarko a nuevas catástrofes frente a las grandes pruebas del futuro: la existencia de un Estado empirico y la del abismo social".

En el mismo texto, más adelante, repite la idea con especial insistencia :

"El Estado era empírico y reposaba sobre un abismo social: he aqui en una frase, la explicación del desastre" (1).

C:ertamente, numerosos y grandes héroes, unos muy conocidos y otros anónimos que en muchos casos fueron a la muerte a sabiendas que las batallas estaban perdidas, expian de alguna manera, las faltas de quienes todo improvisaban desde el aparato del Estado o en la sociedad misma y tuvieron el mérito inextinguible de crear, en generaciones futuras, un optimismo acerca de la capacidad de acción del peruano en las circunstancias más dificiles, que nadie supo prever.

Si todo ésto es materia de constante estudio para mejor conocer la realidad de nuestro pais; parece necesario que nos formulemos la misma interrogante acerca del Estado y de la sociedad del pais invasor para entender qué faciores constituían su fuerza, y cuáles su debilidad. Asi entenderemos mejor por qué se produjo la guerra, y el acontecer internacional después de la guerra hasta nuestros dias.

Ante la interrogante formulada acerca del Estado y de la sociedad en Chile responderemos con una hipótesis -que lo es porque requiere probanza más completa que la que puede dar este breve estudio, y esta hipótes's que consideramos de medular im-

(1) BASADRE, Jorge.- Historia de la República del Perú, tomo V, pp. 2313 y 2314, ed. de 1962, Lima. 
portancia es que en Chile existia un abismo social y sobre ese abismo se erguia un Estado moderno para la época y modernizante. Desde ahora adelantamos dos precisiones: la primera, es que el abismo social en Chile era de distintas caracteristicas al abismo social peruano y va a ser factor influyente en el desencadenamiento de la guerra, y la segunda es que el Estado modernizante chileno aparentemente se parecia a algunos Estados modernizantes. europeos, pero en la realidad se diferenció de éstos en que autolimitó su modernización, sobre todo después de la guerra, o quizás su modernización estaba en parte limitada por la situación de Chile frente a paises capitalistas avanzados.

La Historia del Derecho nos proporciona métodos de análisis para aproximarnos, mediante el estudio de la legislación fundamental, al tratamiento de la hipótesis propuesta. El estudio de la legislación fundamental y el estudio de su difusión y aplicación cuando ello es posible, asimismo, como el conocimiento de la voluntad del legislador que traduce una voluntad politica, es decir de enrumbar el Estado en determinada dirección y no en otra, nos parece importante. Tanto más que se podrá ver cómo hay leyes que legislan más acerca de transacciones o actos jurídicos que se estimaban necesarios para modernizar la sociedad y cómo hay leyes que tratan de enfrentar el problema del abismo social en formas muy propias del siglo XIX, pero dentro de una de las opciones que se presentaban en aquella época. Existia desde luego otra opción en ese entonces: la opción frecuentemente liberal, de ignorar el abismo social y pretender que todo se resuelve declarando que todos son iguales ante la ley. Ciertamente esta declaración solemne no podria faltar en la Constitución chilena de 1833, pero otros articulos de la misma y otras leyes estaban dirigidas a lograr una organización jerárquica de la sociedad, reconociendo y perpetuando el abismo existente.

Nuestro estud o está dirigido a analizar en primer término el sistema politico chileno en el siglo pasado. Esto es posible describiendo las características fundamentales de la evolución de la sociedad chilena de aquella época y analizando las instituciones de la Constitución de 1833 que tuvieron una influencia duradera en el funcionamiento del sistema político como rector de la sociedad chilena. 
La seguridad juridica es lo que en segundo término deseamos analizar mediante algunas disposiciones del Código Civil y del Código de Comercio que favorecen la modernización del país. Orden público en materia de gobierno y seguridad juridica en mater:a de derecho civil y comercial aparecen para el observador extranjero, como los pilares de la legislación. Ello se desprende no solamente de los textos legales, sino de la abundante bibliografia chilena al respecto. la cual en muchos casos es excesivamente apologética de las bondades del sistema para la época. También veremos algunas pocas normas de Derecho Penal que provienen claramente de la necesidad de tomar precauciones de represión frente a los peligros del abismo social: ello está dicho con un vocabulario distinto en las respectivas exposiciones de motivos.

Este ensayo no es ni pretende ser un estudio de fuentes primarias, salvo la consulta directa a los textos legales originales que si se hace. Recurrimos a distintos autores chilenos, y recurrimos también a un estudia de instituciones de Chile hecha por un ilustre peruano hace exactamente cien años, por don Francisco García Calderón en distintos capítulos de su obra "Memorias del Cautiverio", publicada varios años después de su muerte (2). Esa obra, no obstante, haber sido escrita en circunstancias muy adversas de la vida del autor, no cae en la tentación muy humana del apasionamiento.

\section{La Constitución de 1833}

La Constitución Chilena de 1833, vigente hasta 1925, llegó a ser objeto de pocas modificaciones en el siglo XIX. la mayor parte. después de la Guerra del Pacifico.

Esta Constitución significó una reaccón circunstancial contra la anarquía que habia existido desde la Independencia, anarquia vencida en la batalla de Lircay. Este horror a la anarquia se expresa en el proyecto politico de Diego Portales, inspirador de esa Constitución. Influyeron también en su redacción, Andrés Bello, Mariano Egaña y Manuel José Gandarillas.

(2) GARCIA CALDERON. Francisco.-- Memorias del Cautiverio. Libreria Internacional del Perú, Lima, 1949. Ver en especial el Capitulo IV. 
De la voiuntad de los Legisladores que redactaron y aprobaron la Constitución de 1833 se ha dicho con toda precisión lo s!guiente:

“. . como la burguesia de Francia y los padres de la Constitución Americana, los criollos... eran seres humanos con intereses que proteger... Eran propietarios de la tierra y controlaban todas las instituciones productivas de Chile; tenian el poder de facto y lo querian de jure..." (3).

La Constitución de 1833 y las prácticas electorales a que su aplicación dió lugar, otorgaron al Presidente de la República un cúmulo de atribuciones y un poder de decisión pocas veces visto en América Latina. Mientras que en algunos paises del Continente se creyó que disminuyendo las atribuciones del Presidente y aumentando las del Congreso se combatiria la tendencia al golpe de Estado y al caudillismo, los constituyentes chilenos de 1833 pensaron lo contrario. Un presidente de la República fuerte pero no "caudillo" era necesario para mantener el orden público y la vigencia de la Constitución. El Presidente podía ser reelegido para un período inmediato por una vez y cada periodo presidencial duraba cinco años. Así, entre 1831 y 1879 . Chile tuvo los siguientes presidentes: Prieto (1831-1841), Bulnes (1841-1851), Montt (1851-1861). Pérez Mascayano (1861-1871), Errázuriz Zañartu (1871-1876) y Aníbal Pinto (1876-1881) a quien sucederia Domingo Santa María (1881-1886) bajo cuya presidencia se firmó el Tratado de Ancón.

Las atribuciones del Presidente de la República están bien ciescritas por el distinguido historiador chileno don Ricardo Donoso (4). Dice lo siguiente:

"La Constitución de 1833... dotó al Presidence de la "República de tal cúmulo de funciones que lo convirtió. "como se ha observado con razón, en un verdadero mo"narca con un titulo democrático... Podía otorgar em-

(3) P.V. SHAW. - The Early Constitutions of Chile (New York, 1930), citado por BLAKEMORE Harold: Gobierno chileno y salitre inglès: Bal. maceda y North. Editorial Andrés Bello, Santiago, 1977.

(4) DONOSO, Ricardo.- Desarrollo politico y social de Chile desde ln Constitución de 1833. Imprenta Universitaria, Santiago, 1942, p. 14. 
"pleos a los miembros del Congreso, designar a todos "los empleados de la administración pública, incluso los "jueces, someter proyectos de ley, vetar las leyes san"cionadas por el Congreso, declarar estados de sitio y "era irresponsable durante el ejercicio de su cargo. Un "Ejecutivo armado de tales atribuciones podía sofocar "en cualquier momento las tentativas de alterar el orden "público, pues la fuerza pública estaba a sus órdenes.

"La fuerza armada es esencialmente obediente y no "puede deliberar, consignaba la Constitución más ade-. "lante, con el propósito de alejar hasta la más remota "posibilidad de ingerencia del ejército en los negocios "públicos. Al suprimirse las asambleas provinciales crea "das por la Constitución de 1828, la Constitución de “1833 propendió a establecer la más rápida centraliza"ción administrativa y politica. Dentro de ese marco le"gal se va a desenvolver la vida chilena a lo largo de "varios decenios".

Tanto el Presidente, como los Senadores eran elegidos por sufragio indirecto. Para ser Senador se requeria gozar de una renta anual de no menos de mil pesos. Para ejercer el derecho de sufragio se requeria haber cumplido veintiún años de edad, saber leer y escribir, no ser sirviente doméstico, ni hallarse procesado como reo de delito que merezca pena aflictiva o infamante. El sistema electoral era censitario, sistema generalizado en la Europa de ese entonces, excluyendo del mismo a gran parte de la población (5).

Don Francisco García Calderón, años después nos da una ićea de cómo se desarrollaban las elecciones:

"Se practicaron a fines de 1881 y principios de 1882 , "elecciones populares de senadores, diputados y munici"palidades. Me encontraba entonces prisionero en Qui"llota, y tuve ocasión de ver que aún cuando habia can"didatos apoyados por el Gobierno y otros que soste"nian la oposición, que según se me dijo, contaban con

(5) El texto de la Constitución de 1833, con las leyes modificatorias de ésta, ha sido consultado en los "Estudios políticos y constitucionales de José Victorino LASTARRIA, edición de 1906, Santiago, Imprenta, Litografia y Encuadernación Barcelona, y en "Constituciones de Chile, Franctia. Estados Unidos..." de Julio BAFADOS ESPINOSA, Roberto Miranda, editor, Santiago, 1829. 
"la voluntad de la mayoría de los electores, la elección

"favoreció a los candidatos oficiales; y no hubo esa lu"cha o siquiera esa agitación que es natural, y que exis"te dondequiera que hay elecciones populares. La expli"cac'ón de este hecho se me dió por algunos vecinos. La "autoridad politica, me dijeron, tiene como deber prin"cipal el triunfo del Gobierno en las elecciones. Si lo "consigue, permanece en su puesto; y si es lo contrario, "se le reemplaza inmediatamente" (6).

¿Cómo podemos explicarnos la vigencia de la Constitución de 1833 durante tantos años? ¿Cómo podemos explicarnos que no se hayan producido golpes de Estado o levantamientos militares como en otros paises de América Latina?

Después de años de conmociones internas, los grandes agricultores terratenientes apoyaron la aplicación enérgica de la nue. va Constitución de 1833, que de mantenerse en vigencia como efectivamente ocurrió, les garantizaba una paz interna, necesaria para su prosperidad (7). Lo mismo ocurria con los comerciantes de Valparaiso, chilenos y extranjeros. Valparaiso era puerto próspero ya que era el primer puerto que tocaban las naves en la costa del Pacifico, después de un largo viaje de Europa por la vía tel Estrecho de Magallanes. Por épocas va a ser inclusive un puerto de depósito de mercaderías en tránsito al Callao.

A diferencia de lo que ocurrió en otros paises latinoamericanos, los grandes terratenientes llegaron a percibir que tenian intereses comunes que los unían. Dedicábanse a la ganaderia pero sobre todo a la producción de trigo. Esta producción, tradicionalmente destinada al consumo del Perú, encontró mercados en California y Europa en diversos momentos, entre 1840 y 1860. Esto colocó a los hacendados en estrecha relación con los comerciantes exportadores de trigo y puede decirse que los hacendados se modernizaron. "hacia afuera" es decir cuidaron la eficiencia

(7) DONOSO, Ricardo, op. cit., p. 11. También en CAMPOS HARRIET.Historial Constitucional de Chile, Editorial Juridica de Chile, Santiago. 1956, páginas 208 y 209. El libro de CAMPOS HARRIET contiene una útil historia cronológica de los sucesivos gobiernos chilenos. Sin embargo, al tratar acerca de la Guerra del Pacifico, contiene adjetivos que no son propios de un libro de Derecho o de Historia. 
de la comercialización de sus productos (8). Pero además hay un factor geográfico único en América Latina. La mayor parte de la población del pais y la mayor parte de las propiedades productoras de trigo y de ganado se hallaban en el Valle Central de Chile, que se extiende de norte a sur y entre la cordillera y el mar. El Valle Central no tiene accidentes geográficos que sean obstáculos serios a los transportes, y pronto la ciudad de Santiago se convirtió en el centro de poder politico del valle.

La existencia de una unidad geográfica interna y la circunstancia de una creciente prosperidad económica por la exportación de trigo fueron factores que crearon entre los grandes terratenicntes una comunidad de intereses fácilmente percibida por ellos m: $\mathrm{s}$ mos (9). Por tanto la mayor parte de hacendados y de comerciantes apoyaron las ideas de Diego Portales, el inspirador de la Constitución, e igualmente la aplicación continuada de la Constitución que les permitirá participar en el poder como clase política o clase dirigente. Tanto es asi que la Constitución restablece los mayorazgos, lo cual refuerza la permanencia de las grandes propiedades agricolas.

Don Diego Portales fue ministro del Presidente Prieto en dos oportunidades: de 1830 a 1831 y de 1835 a 1837 . Murió asesinado. Nunca pretendió la presidencia de la República, cosa extraña en un estadista latinoamericano. Siendo ministro, organizó al Estado dándole una estructura de mando autoritaria, pero impersonal. Tanto se ha escrito en Chile sobre Diego Portales que es difícil separar la leyenda de la realidad, tanto más ahora en que ha sido convertido en simbolo político de un gobierno que en la realidad no se identifica con su pensamiento.

Portales tuvo ideas en materia de politica interna así como de política internacional, que expresados a través de sus actos, causaron indudable impresión entre sus contemporáneos, e hicieron

(8) BAUER, Arnold. - Chilean Rural Society from the Spanish Conquest to 1930, Cap. 3.

(9) BURR, Robert N.-- By Reason or by Force: Chile and the balancing of power in South America 1830-1905. University of Los Angeles Press, pp. 14-16. También existió un importante desarrollo de la minería del cobre. 
ver a hacendados y comerciantes que la garantia de sus intereses particulares pasaba por la realización de un interés nacional interno de orden, e internacional, de hegemonía naval, comercial y militar.

En carta que escribe a su socio Cea (1822), Portales se declara partidar'o "de un gobierno fuerte, centralizador, cuyos hombres sean modelos de virtud y patriotismo y asi enderezar a los ciudadanos por el camino del orden y de las virtudes" (10). Desea un gobierno poderoso, pero tuvo la rara habilidad de no ser contrario a la fiscalización de los actos del Poder Ejecutivo. Estas ideas aparecen claramente en la Constitución de 1833.

"Restaurar la autoridad del gobierno, del poder supe"vior a los hombres y a los partidos, inmutable, invaria"ble, eterno, fue su preocupación cardinal; inculcar el "hábito de obedecer «por el peso de la noche». como "con gráfica expresión decia el ideal de su acción polí "tica. Nada de ésto se podia obtener sin asegurar el "mantenimiento, sobre todo, del orden público «el resor"te principal de la máquina». Ese sería la deidad a la "que habrian de prestar incondicional acatamiento los "organizadores de la República y los gobernantes de un "tercio de siglo" (11).

Portales elabora las metas duraderas de la política exterior chilena: mantener un equilibrio de poder entre los paises cercanos a Chile para evitar el surgimiento de un pais limitrofe poderoso frente al cual Chile pueda llegar a estar en inferioridad de condiciones económicas, militares, politicas; y el fortalecimiento de la vocación naritima de Chile. La guerra contra la Confederación Perú-Boliviana sintetiza estas dos politicas. Portales inicia la guerra para destruir a la Confederación, con poco entusiasmo inicial de sus compatrotas. El asesinato de Portales, en plena contienda enfervoriza a quienes antes eran tibios frente a la guerra, y la victoria chilena, crea un sentimiento nacional perdurable que consciente o inconscientemente queda vinculado a las ideas portalianas y a su mejor expresión: la Constitución de 1833. Dicha guerra no habría sido posible sin una fuerza naval

(10) CAMPOS HARRIET, op. cit. pp. 215-216.

(11) DONOSO, Ricardo, op. cit., pp. 10-11. 
importante. En sus instrucciones a Blanco Encalada al iniciarse las operaciones bélicas contra la Confederaciốn Perú-Boliviana, en 1837, Portales le escribe lo siguiente: "las fuerzas navales deben operar antes que las militares, dando golpes decisivos. Debemos dominar para siempre el Pacifico: ésta debe ser su máxina ahora y ojalá fuera la de Chile para siempre" (12).

Se nota lo que se conoce del pensamiento de Portales, en quienes años después, dan los pasos decisivos que llevan a Chile a entrar en guerra con el Perú y con Bolivia.

Como una curiosa paradoja frente a lo que iba a ser el destino y voluntad de conquista de Chile en la Guerra del Pacífico. el articulo primero de la Constitución de 1833 señalaba los límites geográficos del territorio chileno. Decia así:

"El territorio de Chile se extiende desde el desierto de Atacama hasta el Cabo de Hornos y desde la Cordillera de los Andes hasta el Mar Pacifico, comprendiendo el Archipiẻlago de Chiloé, todas las islas adyacentes y las de Juan Fernández" (13).

En el litigio con Bolivia sobre el litoral de este último pais, antes y después de la guerra de 1879 , se escribió mucho acerca del signif "cado del vocablo "desde" antepuesto a la expresión "Desierto de Atacama", pretendiendo varios autores chilenos de Derecho Internacional que la palabra "desde" significaba la inclusión del desierto en su territorio, mientras Bolivia sostenia que tal pa-

(12) BARROS VAN BUREN, Mario.- Historia Diplomática de Chile, Ediciones Ariel, Barcelona, 1970. En la pág. 114 se reproduce 'os párrafos principales de la carta de Portales a Blanco Encalada en los cuales están sintetizados tanto sus ideas sobre el predominio maritimo de Chile, como sus convicciones acerca de la necesidad que desaparezca la Confederación Perú-Boliviana. La obra de BARROS VAN BUREN debe ser consultada con precaución. Una buena parte del libro está dedicada a las relaciones de Chile con el Perú por la importancia que el Perú ha tenido para la politica internacional chilena. Sin embargo, en la bibliografia peruana que usa están ausentes del todo las obras de don Jorge $\mathrm{Ba}$ sadre y de don Alberto Ulloa. Utiliza como obra de consulta reciente un respetable texto escolar peruano.

(13) LASTARRIA, José Victorino, op. cit., p. 229. 
labra era excluyente del mismo (14). En todo caso el artículo primero de la Constitución era tan incómodo después de la guerra, que fue suprimido por ley de reforma constitucional de 10 de agosto de 1888 , pues el departamento peruano de Tarapacá ahora conquistado por Chile nunca habia estado en litigio con ese pais y menos aún, Tacna y Arica que exceden de lejos los limites imprecisos del desierto de Atacama.

Para precisar nuestras conclusiones sobre la Constitución misma podemos decir que fue un instrumento eficaz en su época para que el Estado chileno entrase en un largo proceso politico de estabilidad institucional $y$ de legalidad que permitia la modernización del Estado mismo y de los sectores sociales más poderosos del pais.

Ahora bien, es necesario recalcar que las condiciones poll$t$ cas, económicas, sociales $y^{\prime}$ geográficas que fueron indispensables para permitir la larga duración de la Constitución, no son suficientes para explicar este fenómeno inusual en América Latina. Si bien los constituyentes de 1833 hicieron una constitución autoritaria y centralista, incluyeron en ella - unos por convicción propia y otros por pragmatismo- diversas disposiciones que legitimaban la Constitución incluyendo en ella las normas sustantivas sobre derechos de las personas y forma de gobierno que eran consideradas indispensables por el Derecho Constitucional de esa época y lo siguen siendo por el Derecho actual.

(14) EYZAGUIRRE, Jaime.- Chile y Bolivia, esquema de un prcceso diplomático, tercéra edición, Edit. Zig-Zag, Santiago, 1963. En la página 26 se encuentra la argumentación semántica algo forzada sobre el "desde" el desierto de Atacama. Sobre posiciones peruanas acerca de la mediterraneidad de Bolivia, es indispensable leer la opinión del gran internacionalista don Alberto ULLOA en su libro "Posición Internacional del Perú". Lima, 1941, en el Capitulo V, pp. 287 y 288 y el articulo de don Jorge Basadre titulado "El corredor boliviano por Arica, en su libro "Apertura". Lima, 1978, pp. 51-87. Los puntos de vista bolivianos acerca del litoral, del salitre y su régimen legal, de y de los problemas de Derecho Internacional correspondientes, pueden consultarse en "Las Relaciones Internacionales en la Historia de Bolivia", de Valentin ABE. CIA BALVIVIESO, La Paz, 1974; y en "Guano, salitre y sangre: Historia de la Guerra del Pacifico", de Roberto QUEREJAZU CALVO. Cochabamba, 1979. Sobre la situación económica de Bolivia a mediados del siglo XIX, ver "Bosquejo Estadístico de Bolivia", de José M. DALENCE, La Paz, 1975 (reedición). 
La Constitución declaraba el origen popular y representativo del gobierno en su articulo $2 \circ$ (aunque en otros articulos introdujese limitaciones a esa representatividad popular), la igualdad de todos los habitantes ante la ley, la inviolabilidad de la propiedad privada, el derecho a publicar opiniones sin censura previa (art. 12), la inmunidad parlamentaria (art. 14), la potestad de legislar como propia de las Cámaras legislativas (art. 40), la independencia de la administración de justicia (art. 108). El capitulo $\mathrm{X}$ de la Constitución declara "las garantías de la seguridad y propiedad", y el articulo 157 expresa que "la fuerza pública es esencialmente obediente. Ningưn cuerpo armado puede deliberar". Sin legitimidad, en el sentido que Max Weber da a esta expresión, no hay Constitución duradera. Todo sistema legal para durar y tener aplicación debe tener legitimidad.

\section{Los Códigos en Chile}

Para quien desea formarse una idea acerca de la legislación vigente en Chile cuando estalla la Guerra del Pacifico, es muy útil la consulta a una edición de los Códigos chilenos y leyes complementarias, hecha con un tiraje de cinco mil ejemplares, en Leipzig. Alemania, por don Carlos Morla Vicuña, funcionario de la representación diplomática chilena en Paris. La corrección de la edición está certificada por don Alberto Blest Gana, Enviado Extraordinario y Ministro Plenipotenciario de Chile en Francia. La certificación está hecha en imprenta y lleva como fecha el mes de setiembre de 1882. La autorización oficial para llevar a cabo dicha edición, emana de un Decreto, de 25 de abril de 1879 suscrito en Santiago por el Ministro Jorge Huneeus, es decir veinte días después de declarada la guerra al Perú por Chile y poco más de dos meses después de la ocupación chilena del litoral boliviano (15).

La coincidencia de fechas entre la guerra y una publicación oficial de Códigos de Chile en Europa puede ser fortuita, fruto de la casualidad. Pero también pudo ser de otra manera. La historia de las relaciones internacionales de Chile registra la labor

(15) "Códigos chilenos", Leipzig, F.A. Brockhaus, 1882. Contiene el Código Civil, el Código de Comercio, Código de Mineria, Ley de Organización y atribuciones de los Tribunales; Leyes complementarias. 
multifacética de don Alberto Blest Gana secundado con don Carlos Morla Vicuña en la doble tarea de evitar compras de blindados y armamento por el Perú a partir de 1879, y de presentar a Chile ante los paises europeos como un pais que "representaba el respeto al derecho convencional y a las libertades modernas... la buena fe y la honradez en el cumplimiento de sus compromisos financieros, "que debía contrastar con el constante desorden que los países europeos solian ver en el resto de América Latina". Al decir de un historiador de la materia, la Legación de Chile en Francia llegó a contratar hasta trescientos agen tes en diversos países de Europa para defender los intereses chilenos durante la Guerra del Pacifico (16). Si dentro de la frenética actividad diplomática llevada a cabo debido a la guerra, es tuvo la edición de Códigos para que el acreedor o inversionista europeo se formara una idea acerca de la seguridad jurídica existente en Chile, no lo sabemos. En todo caso, la edición es muy útil para nuestro trabajo porque permite saber algo sobre las leyes que estaban vigentes en 1879 .

Como ya señalamos anteriormente, nos interesa describir aquellas disposiciones de los Códigos que de manera inequívoca dieron seguridad juridica a la propiedad privada y legislación penal destinada a mantener el orden público. Las grandes familias terratenientes del Valle Central de Chile, que en 1833 "tenían el poder de facto y lo querian de jure" según expresión antes citada de un autor norteamericano, supieron permitir el ingreso a la vida política de prominentes miembros de una clase media en formación. Esta clase media de pequeños propietarios y comerciantes, y de profesionales liberales se convierte en la clase media más importante por su poder y número, de toda la costa occidental de América del Sur y prosperó -entre otros factores- por la prosperidad de Valparaiso y por la ausencia de las contiendas civiles frecuentes en otros paises latinoamericanos.

La creciente clase media necesitaba de la seguridad juridica, y ésta a su vez, contribuia a su fortalecimiento.

(16) BARROS VAN BUREN, Mario.- Op. cit., pp. 374-380. Contiene extractos del Informe de la Legación de Chile en Francia, suscrito por A. Blest Gana, dirigido a su Ministro de Relaciones Exteriores. 
Por otra parte, el crecimiento de aquella clase de desposeidos de tendencias transhumantes y con trabajo eventual en las ha cłendas hizo aún más necesaria la seguridad juridica de la propiedad para el dueño, frente a dichos trabajadores eventuales y frente a los "inquilinos" del fundo, categoría social distinta.

El Código Civil de Chile entró en vigencia en 1857 y fue obra del gran jurista don Andrés Bello. La calidad juridica del Código ha sido ampliamente reconocida, y la precisión y sencillez de su redacción llaman la atención.

Mediante este Código se introduce en Chile una institución muy avanzada para la época en América Latina: que es la inscripción obligatoria en un Registro, llamado el "Registro del Conservador" de la transferencia de la propiedad de los bienes inmuebles, asi como los derechos de uso constituídos en bienes inmuebles, los derechos de habitación o de censo y el derecho de hipoteca (art. 686), salvo la tradición de las minas que se regirá por lo dispuesto en el Código de Minería. Asimismo, el artículo 688 del Código establece que la posesión legal de una herencia no habilita al heredero para disponer de manera alguna de un inmueble, mientras no proceda, entre otros requisitos, la inscripción en el Registro Conservatorio; y finalmente, el articulo 724 establece que "si la cosa es de aquellas cuya tradición debe hacerse por inscripción en el Registro del Conservador, nadie podrá adquirir la posesión de ella sino por este medio".

De acuerdo al artículo $371^{\circ}$ de la Ley de Organización y Atribuciones de los Tribunales, de 15 de setiembre de 1875, "Son Conservadores los ministros de fe encargados del registro conservatorio de bienes raíces o del registro de comercio o de uno y otro".

En el Título XXIII del Código que trata de la compraventa, el articulo $1801^{\circ}$ establece que la venta de bienes raíces, servidumbres y censos, y la de una sucesión hereditaria no se reputa perfecta mientras no se haya otorgado escritura pública.

Por lo expresado anteriormente, el Registro es en Chile, constitutivo de la propiedad y de otros derechos reales sobre bienes inmuebles. Es ésta la mayor seguridad juridica que puede tener el dueño sobre su propiedad raiz. 
Asi se creaban las condiciones para la existencia de un mercado seguro de compra venta de inmuebles y un mercado de créditos, elementos necesarios para una rápida modernización capitalista.

La legislación penal chilena de ese entonces, nos interesa para fines de nuestro estudio en un punto importante: la persistencia en Chile de la "pena de azotes". El Código Penal, promulgado en el año 1874 confirmó lo dispuesto en la ley de 1850 que mandaba abolir dicha pena que se aplicó con mucha frecuencia hasta ese entonces. Sin embargo, dos años después de la promulgación del Código Penal, por ley de 3 de agosto de 1876, se restablece la pena de azotes. El castigo consistia en veinticinco azotes por cada seis meses de presidio sin que en ningún caso pudiera imponerse más de cien azotes en virtud de una misma sentencia... El articulo $3^{\circ}$ de dicha ley tiene una redacción muy especial. Dice asi:

"el culpable de robo o de tentativa de este crimen será castigado con pena de muerte, siempre que al mismo tiempo se hiciese reo de homicidio, violación u otra injuria grave contra las personas".

A estarse por esta redacción pareciera que el delito que más preocupaba al legislador era el robo.

El reglamento de la ley aquí citada establece que si el reo fuese mujer, o varón menor de dieciséis años o mayor de sesenta, se suspenderá la pena de azotes. También manda el reglamento que si el número de azotes impuesto al reo excediera de veinticinco, tendrá derecho de pedir que la pena se divida en fracciones que no bajen de ese número y que medie entre una y otra aplicación un término que no exceda de un mes. La pena será aplicada siempre en las cárceles "y no podrá ser presenciada sino por los presos o detenidos del sexo del castigado".

La razón de la vigencia de la pena del azote, tan degradante, y que en doctrina no se aceptaba en esa época, está en la "proliferación del bandolerismo", según la Exposición de Motivos de la Edición que contiene los Códigos y leyes aqui citados. 
El "bandolerismo" a que se refiere la Edición de los Códigos de 1879 , se refiere no sólo a ese problema social. El bandolerismo que sin duda existió era efecto del carácter transhumante del estrato más bajo y desposeido de la población chilena, estrato social que no conocia trabajo fijo o permanente.

El establecimiento de la pena de azotes parece reflejar un deseo de control sobre los temidos excesos de esa transhumancia, por el temor natural a que da lugar la aplicación de esa pena.

\section{Apreciaciones de Garcia Calderón}

En el capitulo VIII de sus Memorias, don Francisco Garcia Calderón hace un interesante análisis acerca de las clases sociales en Chile, que tiene que ver con el "bandolerismo" y la severidad de la legislación penal.

"La población de Chile - nos dice - por causa del bie"nestar material, se puede clasificar de este modo: ri"cos, de mediana fortuna y pobres".

"No son muchos los de la primera clase, porque la ri"queza no está distribuida sino más bien concentrada "en pocas manos; y por el contrario son muchos los de "mediana fortuna, entre los cuales se cuentan no sólo "los propietarios de fincas, profesores de artes liberales, "industriales y artesanos, sino también administradores "de fundos rústicos y otros que tienen determinado "bienestar porque ganan lo suficiente para la satisfac"ción de sus necesidades, y a veces para hacer econo"mias y ahorros".

"Al lado de estas dos clases se encuentra el pobre, que "no tiene hogar, que no forma familia y vive de su tra"bajo manual cuando halla ocupación. Esta es la clase "bastante numerosa a que se da el nombre de rotos".

Más adelante, Garcia Calderón dice que como los salarios en el campo son bajos y las familias muy numerosas, los "rotos" emigran buscando subsistencia.

"Esta vida errante hace del roto un nómade y el cambio "frecuente de residencia, la lucha contra la naturaleza y "los esfuerzos que hace para ganar el pan diario lo acos- 
'tumbran a la fatiga y le dan el gusto por las aventu"ras" (17).

Luego, el autor añade un tema de fundamental importancia:

"De esto resulta que hay en Chile una clase errante y "que no tiene porvenir. Cuando sale del pais por milla"res, como sucedió en 1868 y 1872 para construir en el "Perú los ferrocarriles de Mollendo a Arequipa y Puno "y del Callao a La Oroya nada se puede temer en cuanto al orden público. Mas cuando nada despierta en el "exterior el espiritu aventurero del roto, en el interior "hay serios peligros para las clases acomodadas. Los "rotos, no teniendo trabajo en los campos, afluyen a las poblaciones y son una amenaza formidable para el ve"cino de ellas. Así sucedió en 1878. Los rotos, que se "habian reunido en Santiago... eran numerosísimos; y "la población aterrada con ellos, temia que de un mo"mento a otro hubiera una conmoción social. Para con"jurar el peligro se pensó en declarar la guerra a la Re. "pública Argentina; y como la diplomacia hizo desapa"recer todo pretexto para ella, se dirigió la vista a Bo"livia y poco después al Perú".

Un personaje chileno manifestó a García Calderón que:

"la guerra tuvo por causa el hambre: teniamos una "población no pequeña que pedia pan y no podiamos "dárselo; y fue preciso llevarla a otra parte y buscar "nuestra seguridad interior en la guerra externa" (18).

Se pregunta entonces García Calderón:

"¿qué se hace en Chile para curar esta gangrena social? "a mi juicio, absolutamente nada. Las leyes y las cos"tumbres alejan cada dia más al roto del hombre ci"vilizado: las leyes porque preservan el azote; y las "costumbres, porque los que valen algo desprecian al "roto y lo estigmatizan; y si alguna vez se lo elogia, "como sucede ahora, que la prensa atribuye al valor "del roto el mérito de las victorias alcanzadas en el "Perú, ese encomio no sirve sino para avivar pasiones".

(17) y (18) GARCIA CALDERON, Francisco, op. cit., pp. 182-183. 
En el capitulo siguiente, el autor vuelve sobre el tema de la pena de azotes: dice que el Perú los abolió poco después de su independencia, pero Chile conserva esa pena que en la realidad sólo se aplica a los rotos, y nunca a personas de condición social distinta.

En diversos capitulos de sus Memorias, don Francisco Garcia Calderón repite la idea que, "si no se modifica la situación interior de Chile, en un tiempo más o menos largo, la revolución será inevitable" (19), sobre todo por "la honda distancia que separa al roto del hombre civilizado". Las amenazas a la paz pública son de carácter más bien social que político, y como todos los dirigentes de los partdos están de acuerdo sobre ellos, buscan la paz interna a todo trance, evitando las conmociones politicas.

Si colocamos estas ideas de García Calderón, escritas en 1883. dentro del contexto de la historia posterior de Chile, notamos como las conmociones que sufrió dicho país en la década de los años veinte y de los años treinta de este siglo están muy vinculadas con la incorporación de las clases medias a la politica primero, y de la clase obrera después (recuérdese el Frente Popular). La estructura de clases de la sociedad chilena ha variado sustancialmente desde la época de la Guerra del Pacífico, pero es interesante notar como los partidos políticos chilenos, en mayor grado que los de otros paises latinoamericanos, han reclamado tener bases sólidas en determinadas clases sociales. La estrecha vinculación entre la estructuras sociales y la vida política, hecho que dentro del contexto de la época percibió claramente don Francisco Garcia Calderón. sigue siendo una característica marcada de la sociedad chilena.

\section{Conclusiones}

Al estallar la Guerra del Pacifico, Chile es un pais que ha gozado de una estab:lidad politica de excepción en Hispanoamérica, desde 1833. La Constitución de ese año legitima un gobierno republicano, democrático y respetuoso de las libertades ciudadanas. La lectura más atenta de la Constitución nos muestra una democracia limitada, una suerte de "república aristocrática" en la cual gobiernan y opinan terratenientes poderosos, grandes comerciantes, acompañados en oportunidades por personas provenientes de una

GARCIA CALDERON, Francisco, op. cit., p. 144. 
naciente y próspera clase media. Estos grupos se manifiestan a través del Parlamento y los Ministros, pero el régimen otorga al Presidente de la República un cúmulo de atribuciones pocas veces vista en América Latina. Asi entonces se forma una "clase politica" cuyos miembros van participando en distintos gobiernos. El Presidente, un "primus inter pares" puede llegar a gobernar hasta diez años seguidos mediante una reelección y tiene amplios poderes, pero éstos no dependen de su persona. No es un caudillo carismático. Esta institucionalización del poder, permite algo muy importante: una relativa continuidad en la toma de decisiones en el gobierno. Conscientemente o no, se va creando una politica internacional y políticas frente a problemas internos. Estamos entonces ante un Estado que se modernizó con rapidez, y que a su vez es capaz de modernizar al pais, en el sentido de hacerlo entrar en el mundo de las transacciones capitalistas y de la incipiente tecnologia moderna.

Este Estado modernizado no puede ni pretende modernizar a todo el pais. Se apoya sobre un "abismo social" que constituye un peligro latente. Las caracteristicas de la evolución económica de Chile, cuyo tratamiento escapa a este estudio, y el incremento demográfico crean una clase desposeida y transhumante que no recibe ningún beneficio de la Constitución pues está excluida hasta del sufragio, pero si recibe un especial castigo de las leyes penales. En un mundo donde la legislación social estaba por crearse, la ley penal era insuficiente para contener "el peligro de los rotos". Entonces don Francisco Garcia Calderón nos dice que ve un peligro de "revolución social" en Chile, y que ésta se evitó mediante la guerra internacional. Asi esa clase desposeida podia seguir emigrando al desierto salitrero arrebatado a Bolivia primero y al Perú después, y podia enrolarse en los numerosos ejércitos que Chile tuvo que movilizar para la guerra y la invasión.

Con la victoria en la Guerra del Pacifico, Chile acrecentó en un tercio su territorio. La conquista del norte permitió una mayor migración de mano de obra sin trabajo hacia las oficinas salitreras y además dió rentas al Fisco de una magnitud tal que durante los años posteriores a la guerra hubo dinero suficiente para realizar numerosas obras públicas que también daban trabajo a los desocumpados y generaban una notable circulación de riqueza en otros sectores de la sociedad. 
Sin embargo aqui lilegamos a las limitaciones de la modernización del Estado y de parte de la sociedad en Chile. La seguridad juridica que la vigencia de la Constitución y del Código $\mathrm{C}$ vil de Andrés Bello creó en Chile fue - aparte de lo que hubiesen pensado los legisladores en su momento-, una condición para el desarrollo de un capitalismo comercial que desplazara al auto-consumo o a las relaciones patriarcales. Pero el proceso de modernización, que supone la incorporación de tecnologias nuevas no se completa si no hay industrialización. Puede discutirse si un proceso de industrialización era posible en Chile en 1884. Pero no sólo no hubo tal, sino que las minas de salitre del norte recién conquistado pasaron rápidamente a propiedad de capitalistas ingleses y en poco tiempo estuvieron bajo el monopolio de un aventurero, el inglés John Thomas North (20).

Ya sea por la posición de Chile frente a las grandes potencias industriales de la época: Gran Bretaña, Alemania, Francia en materia de comercio y relaciones financieras; ya sea por ideologia liberal en lo económico de los dirigentes políticos chilenos, el Estado no estaba preparado para recibir los frutos de sus conquistas bélicas. Aquí estaba el limite al cual había llegado la modernización del Estado chileno y de sus grupos dirigentes. La ideología de libre empresa absoluta permitió a John Thomas North adquirir un ferrocarril que transportaba salitre. Los mineros peruanos, chilenos, ingleses de las minas circundantes tuvieron que venderlas a North por las dificultades que éste puso para el transporte del salitre de terceros en ese único medio de locomoción que había. Asi siguió monopolizando oficinas de salitre hasta su muerte, y en suma gran parte de las minas fueron inglesas, con grandes remesas de utilidades a Gran Bretaña, hasta que terminó la riqueza

(20) BLAKEMORE, Harold, op. cit. Esta obra analiza los mültiples mecanis. mos de la transferencia de la propiedad de las salitreras a súbditos británicos mediante el estudio de las operaciones financieras y presiones de John Thomas North. Para estar a la altura de su fama de "rey del salitre". compró una gran mansión cerca de Londres cuya cúpula central se veia a millas de distancia "y en cuyo salón principal estaban colocadas dos enormes puertas de hierro decoradas tomadas de la catedral de Lima por las tropas chilenas en la Guerra del Pacifico" (Cita textual, pág. 52). Es significativo el hecho que una pieza no desdeñable del botin cuantioso del saqueo de los edificios públicos de Lima fuese a parar a la metrópoli del imperio más grande de esa época. 
del salitre con el invento de fertilizantes sintéticos en las primeras décadas de este siglo.

En el caso de Tarapacá, las oficinas salitreras que fueran adquiridas por el Estado peruano por ley del año 1875 -aunque la adquisición fuese imperfecta- pasaron rápidamente a ser propiedad en su inmensa mayoria, de súbditos británicos después de la conquista de Tarapacá por Chile. Curiosa paradoja ésta, que ilustra bastante bien las limitaciones de la modernización en Chile, a la vez que las virtudes y carencias de la legalidad - Constitución y leyes de la época- que le sirvieron de base.

Lima, octubre de 1983 